\title{
Molecular Profiling of Potential Human Prostate Cancer Stem Cells
}

Vitale Miceli ${ }^{1}$, Letizia Cocciadiferro', Zarcone Maurizio', Kyung-Sun Kang ${ }^{2}$, James E. Trosko ${ }^{3}$ and Giuseppe Carruba ${ }^{1 *}$

${ }^{1}$ Department of Oncology ARNAS-CIVICO, Piazzale N. Leotta 90127 Palermo, Italy

${ }^{2}$ Adult Stem Cell Research Center Dept. of Veterinary Public Health College of Veterinary Medicine Seoul National University Seoul, Republic of Korea

${ }^{3}$ On Sabbatical Leave from Department of Pediatrics \& Human Development College of Human Medicine Michigan State University East Lansing, Michigan 48824

\begin{abstract}
We have investigated the expression of Oct-4, Suz-12, and Cripto-1, as presumptive "stemness" genes, and of connexin 43 (Cx43), Cx32 and androgen receptor (AR), as cell differentiation genes, in two human prostate cancer cell lines, PC3 and LNCaP. This aiming to define molecular profiles of prostate cancer stem cells for a better understanding of prostate carcinogenesis and tumor progression, as well as for prognostic or therapeutic purposes. Cells were grown in 3-dimensional (3D) cell cultures to favor clonal expansion of cancer stem and early progenitor cells, and compared to cells grown in 2-dimensional (2D) cell cultures. Under 3D culture conditions, LNCaP cells and PC3 cells generated cell spheroids and aggregates, respectively. Under this condition, the expression of candidate stemness genes markedly increased with respect to $2 \mathrm{D}$ cell cultures up to day 4 of culture but drastically fell thereafter, while connexin genes gradually decreased up to day 6 , where upon, a rise of AR transcript could be observed. Our data suggest that Oct- $4^{+} / \mathrm{Suz}-12^{+} /$Cripto- $1^{+}$cells represent human prostate cancer stem or early progenitor cells and that this molecular profile could be used to screen several tumor promoters and/or chemotherapeutic agents, to obtain prognostic indication and to predict response of patients to treatment.
\end{abstract}

Keywords: Prostate cancer stem cells; Stemness genes; Differentiation genes

\section{Introduction}

While the cellular origin of cancer remains unresolved, two long-time competing hypotheses, namely the "stem cell theory" [1] and the "de-differentiation theory" of cancer [2], have enticed new interest because of recent advances in stem cell research and molecular oncology. It has long been noted that the disciplines of developmental biology and oncology share interests in common factors, such as genetic/environmental and dietary factors, which are associated with teratogenesis and carcinogenesis [3]. The ideas that cancer is a "disease of cell differentiation" [4], a "stem cell disease" [5] and "oncogeny as partially-blocked ontogeny" [6] depend on the original target cell, that ultimately leads to cancer, being an adult stem cell. Even though each tumor contains genotypic/phenotypic-diverse cells, they all seem to have originated from a single "cancer stem cell", in that they are clonally-derived $[7,8]$.

The recent isolation of human embryonic stem cells $[9,10]$, including the definition of an embryonic stem cell as having the ability to form teratomas when placed in an adult organism, and the demonstration of "cancer stem cells" [11-16], provide some indirect, but strong evidence, for the stem cell origin of cancers. On the other hand, adult human stem cells have also been isolated or identified from human kidney [17,18], breast [19], pancreas [20], mesenchyme [21], liver [22] and prostate [23-25].

Given the recent interest in the potential use of embryonic and adult stem cells for basic and applied research, including testing the origin of human cancer, attempts have been made to characterize markers that would identify these stem cells.

Oct-4 is a transcription factor, discovered in 1990 [26] that has been found to be expressed in ovulated oocytes, mouse pre-implantation embryos, ectoderm of the gastrula and primordial germ cells, as well as in embryonic stem cells but not in their differentiated daughters [27]. Subsequent studies suggested that Oct-4 might be a specific gene marker required for totipotency [28]. The Oct- 4 gene has also been shown to be expressed in some human malignant cells but not in normal somatic tissues $[29,30]$. Oct- 4 was reported to be abundantly expressed in multiple adult human stem cells and in a breast cancer stem cell line derived from the normal breast stem cells [31]. Oct- 4 expression was also revealed in human bladder cancer [32], several canine tumors [31], and human oral squamous cell carcinomas [33], with frequencies of the Oct- 4 positive cells, as compared to Oct- 4 negative cells within each tumor, varying dramatically. However, some recent papers have cast doubt on the use of Oct- 4 as a marker for adult stem cells [34], and the reasons for the current discrepancies in the literature remains unclear.

Another presumptive marker of stem cells is Suz-12. It belongs to a polycomb group of proteins forming repressor complexes that control cell fate, stem cell renewal, and cell division [35]. Polycomb genes and their associated proteins have been considered as "key guardians of stemness" [36]. Suz-12 is over-expressed in a variety of human tumors [37] and increased Suz-12 in cancer cells is believed to alter the targeting of silenced genes [38]. Gene silencing through promoter hypermethylation and other extensive epigenetic changes, which act as alternatives to point or deletion mutations to disrupt tumor suppressor gene function, have repeatedly been documented in cancer [39].

Another putative stem cell marker, the human Cripto-1 (CR1), belongs to the epidermal growth factor (EGF)-CFC family and

${ }^{*}$ Corresponding author: Giuseppe Carruba, MD, Ph.D., Experimental Oncology Unit, Department of Oncology, M. Ascoli, ARNAS-Civico, Via Carmelo Lazzaro 2, 90127 Palermo, Italy, Tel: +39-091-666-4348; Fax: +39-091-666-4352; E-mail: lucashbl@unipa.it

Received June 24, 2011; Accepted August 03, 2011; Published August 11, 2011

Citation: Miceli V, Cocciadiferro L, Maurizio Z, Kang KS, Trosko JE, et al. (2011) Molecular Profiling of Potential Human Prostate Cancer Stem Cells. J Stem Cell Res Ther S7:001. doi:10.4172/2157-7633.S7-001

Copyright: ( 2011 Miceli V, et al. This is an open-access article distributed under the terms of the Creative Commons Attribution License, which permits unrestricted use, distribution, and reproduction in any medium, provided the original author and source are credited. 
is structurally related to proteins that have been identified in several vertebrate species [40]. CR-1 can be found in the conditioned medium of several cell lines, where it is probably released by cleavage of the glycosylphosphatidylinositol membrane anchor moiety, suggesting that EGF-CFC proteins can function as secreted or cell membraneassociated proteins [41]. EGF-CFC proteins perform regulatory functions related to cell and tissue patterning during embryogenesis [42] and it has been shown that these proteins maintain the pluripotential and self-renewal capacities of human and mouse embryonic stem cells. They are, therefore, considered stem cell markers. CR-1 is inappropriately re-expressed in a wide range of human epithelial cancers, suggesting a link between stem cells and tumor development and/or progression.

The cancer cells do not have functional homologous or heterologous gap junctional intercellular communication (GJIC), due either to no expression of the gap junction proteins connexins or to their aberrant localization and/or phosphorylation status [43]. Gap junctions have been associated with normal development, growth control, differentiation, wound repair, synchronization of metabolic secretion and electrotonic function in tissues. In addition, several presumptive isolated adult human stem cells have been characterized as being deficient in connexins expression [17,19].

Human primary cell cultures are characterized by having a limited lifespan, due to the Hayflick phenomenon [44]. Because cell lines derived from cancers are immortal, they should contain, if the "stem cell hypothesis" is correct, both "cancer stem" cells and "cancer nonstem" (partially differentiated cells).

Based on this assumption, we have inspected the expression of different alleged stem cell markers in two established human prostate cancer cell lines, PC3 and LNCaP cells, grown in 2-dimensional (2D) and 3-dimensional (3D) cell culture conditions. The main objective of this study was to define molecular profiles of prostate cancer stem cells using cell model systems that are commonly considered representative of androgen-responsive and -refractory human prostate carcinoma. Using conditions that favor the clonal expansion of cancer stem cells, we have found that the expression of all three potential cancer stem cell markers raised initially in both the highly tumorigenic prostate cancer cell line PC3, and the weakly malignant prostate cancer cell line LNCaP, but decreased thereafter presumably as a consequence of a partial cell differentiation, also in accordance to the results of previous studies on other cell model systems [45].

\section{Materials and Methods}

\section{Cell lines}

Androgen responsive LNCaP cells and androgen non-responsive PC3 cells were obtained from the American Type Culture Collection (ATCC, Virginia, USA). Cells were routinely grown and maintained in RPMI medium containing 5\% defined fetal bovine serum (Hyclone, Salt Lake City, UT), $1 \%$ antibiotic-antimycotic, $1 \%$ L-Glutamine (GIBCO, Grand Island, NY), at temperature of $37^{\circ} \mathrm{C}$ in an atmosphere of $5 \% \mathrm{CO} 2$ and $95 \%$ air. Cell having a narrow range of passage number (LNCaP, 25-30; PC3, 62-67) were used for all experiments.

\section{Growth of 2D and 3D cell cultures}

Cells were seeded in ultralow attachment plates (Corning Costar Corp., Cambridge, MA), coated with $0.6 \%(\mathrm{~W} / \mathrm{V})$ agar in $\mathrm{PBS}$ at a density of 200,000 viable cells/mL (3D cell cultures), to foster the clonal expansion of cancer stem cells. Parallel cell cultures were grown on plastic and used as controls. Cells were grown in Keratinocyte serumfree (KSF) medium, supplemented with $5 \mathrm{ng} / \mathrm{mL}$ EGF, $50 \mathrm{ng} / \mathrm{mL}$ Bovine Pituitary Extract (BPE), 1\% antibiotic-antimycotic (GIBCO, Grand Island, $\mathrm{NY}$ ), at $37^{\circ} \mathrm{C}$ in an atmosphere of $5 \% \mathrm{CO} 2$ and $95 \%$ air. Cell spheroids and cell aggregates were collected by gentle centrifugation (800 rpm) after 2, 4 and 6 days culture and dissociated enzymatically (10 $\mathrm{min}$ in $0.05 \%$ trypsin, $0.53 \mathrm{mM}$ EDTA-Na; Invitrogen Grand Island, NY) and mechanically, using a pasteur pipette. The resulting cell suspension was sieved through a $40-\mu \mathrm{m}$ sieve and analyzed microscopically to confirm uniform cell dissociation. If groups of cells were present at a frequency $>1 \%$, mechanical dissociation and sieving were repeated. Cell viability was monitored using the dye-exclusion trypan blue method. Aliquots of the same cell suspension were used at day 2, 4 and 6 for RT-PCR analysis and immunocytochemical assay (ICA). For the latter purpose, separate 2D cell cultures were grown directly on chamber slides and processed as described below.

\section{Reverse Transcriptase-Polymerase Chain Reaction (RT-PCR)}

Total RNA was extracted from aliquots of spheroid-derived cell suspensions at 2, 4 and 6 days, using TRIzol reagent ${ }^{\mathrm{tx}}$ (Invitrogen), according to the manufacturer's instructions. The RNA was dissolved in RNase-free water, and its concentration and purity determined from absorbance at $260 \mathrm{~nm}$ and $280 \mathrm{~nm}$ using a spectrophotometer. Prior to reverse transcription, one $1 \mu \mathrm{g}$ of RNA was treated with $1 \mu \mathrm{L}(1 \mathrm{U})$ of RQ1 DNase (Promega, Madison, WI), in presence of RNaseOUT (Invitrogen), by incubation at $37^{\circ} \mathrm{C}$ for $30 \mathrm{~min}$ and $65^{\circ} \mathrm{C}$ for $10 \mathrm{~min}$. The cDNA was synthesized in a $20-\mu$ l volume containing $1 \mu \mathrm{g}$ RNA, $0.1 \mu \mathrm{g}$ random hexamer primers (Invitrogen), $5 \mathrm{X}$ buffer (Invitrogen), $0.1 \mathrm{M}$ DTT (Invitrogen), $10 \mathrm{mM}$ each of dNTP (Invitrogen), 40U RNase inhibitor (Invitrogen) and 200U of SuperScript ${ }^{\mathrm{Tm}}$ II Reverse Transcriptase (Invitrogen). The PCR was conducted with a GeneAmp ${ }^{\circ}$ PCR System 9700 (Applied Biosystems). We used $\beta$-Actin as internal standard for PCR analysis of Oct-4, Suz-12, Cripto-1, Cx32, Cx43 and AR genes. Qualitative amplification was performed using 35 cycles at $95^{\circ} \mathrm{C}$ for $30 \mathrm{~s}$, specific temperature of annealing for $45 \mathrm{~s}, 72^{\circ} \mathrm{C}$ for $45 \mathrm{~s}$, followed by $72^{\circ} \mathrm{C}$ for $5 \mathrm{~min}$ respectively. The semiquantitative analysis was performed through a condition whereby PCR products accumulate exponentially and their quantity increases in an mRNA-dependent manner. All PCR products were analyzed by gel electrophoresis on $2 \%$ agarose gels with ethidium bromide staining, followed by fluorescence digitization using the software "ImageJ 1.38X" (National Institutes of Health, USA).

The primers' set for each gene were the following: Oct- 4 , for-GAG AAT TTG TTC CTG CAG TGC and rev-GTT CCC AAT TCC TTC CTT AGT G; SUZ-12, for-CTT ACA TGT CTC ATC GAA ACT CC and rev-GGC TGG AAG CTC TTC ATT GAC A; Cripto-1, for-CAC GAT GTG CGC AAA GAG A and rev-TGA CCG TGC CAG CAT TTA CA; Connexin 32, for-GAA TGA GGC AGG ATG AAC TGG ACA GGT TTG and rev-GGG GCA GGG GTA GAC GTC GCA CTT GAC; Connexin 43, for-GGG GCA GGC GGG AAG CAC CAT CTC and rev-TCT CTT ATC CCC TCC CTC TCC ACC CAT CTA CCC; Androgen receptor, for-TGC CAG GGA CCA TGT TTT GCC and revGCC TCA TTC GGA CAC ACT GGC TGT A; $\beta$-Actin, for-CTG GCA CCA CAC CTT CTA C and rev-GGG CAC AGT GTG GGT GAC. 
Citation: Miceli V, Cocciadiferro L, Maurizio Z, Kang KS, Trosko JE, et al. (2011) Molecular Profiling of Potential Human Prostate Cancer Stem Cells. J Stem Cell Res Ther S7:001. doi:10.4172/2157-7633.S7-001

\section{Immunocytochemistry}

Both cells grown directly on slides (2D cell cultures) and from cytospins (3D cell cultures) were processed for ICA of Oct-4, Suz-12, Cripto-1, Cx32, Cx43 and AR gene. The cells were fixed in 4\% formalin for $15 \mathrm{~min}$ at $4^{\circ} \mathrm{C}$ and rinsed twice in $1 \times$ phosphate-buffered saline (PBS, $\mathrm{pH}$ 7.4) for $5 \mathrm{~min}$ each. Endogenous peroxidase activity was removed by incubation in $3 \%$ hydrogen peroxide and non-specific binding was blocked by incubation in "Novocastra ${ }^{\mathrm{TM}}$ Protein Block" (NovoLink ${ }^{\mathrm{TM}}$ Polymer Kit, Novocastra Laboratories, Newcastle, UK) for 5 minutes at room temperature. Primary antibodies used included: (a) a rabbit antihOct-4 polyclonal antibody (dilution 1:200, Chemicon International, Germany); (b) a goat anti-hSuz12 polyclonal antibody (dilution 1:50, Santa Cruz Biotechnology, San Diego, CA); (c) a mouse anti-hCripto-1 monoclonal antibody (dilution 1:10, R\&D Systems, Minneapolis, MN); (d) a rabbit anti-hConnexin 32 (dilution 1:400, Sigma, St. Louis, MO); (e) a rabbit anti-hConnexin 43 (dilution 1:1000, Sigma, St. Louis, MO); (f) a rabbit anti-hAR polyclonal antibody (dilution 1:50, Santa Cruz Biotechnology, San Diego, CA). The slides were incubated with diluted primary antibody for $16 \mathrm{~h}$ at $4^{\circ} \mathrm{C}$. Secondary HRP-conjugated antibody (NovoLink ${ }^{\mathrm{TM}}$ Polymer Kit) was added to slides for $30 \mathrm{~min}$ at room temperature and specific staining was identified following incubation with a solution of the chromogenic peroxidase substrate, diaminobenzidine (DAB)/hydrogen peroxide for 4 minutes. Slides were counterstained with $0.02 \%$ hematoxylin, followed by successive dehydration in ethanol and xylene before mounting of coverslips. Quantitative image analysis was performed using a Leica computerized image analysis system with a Qwin software (Leica Imaging System

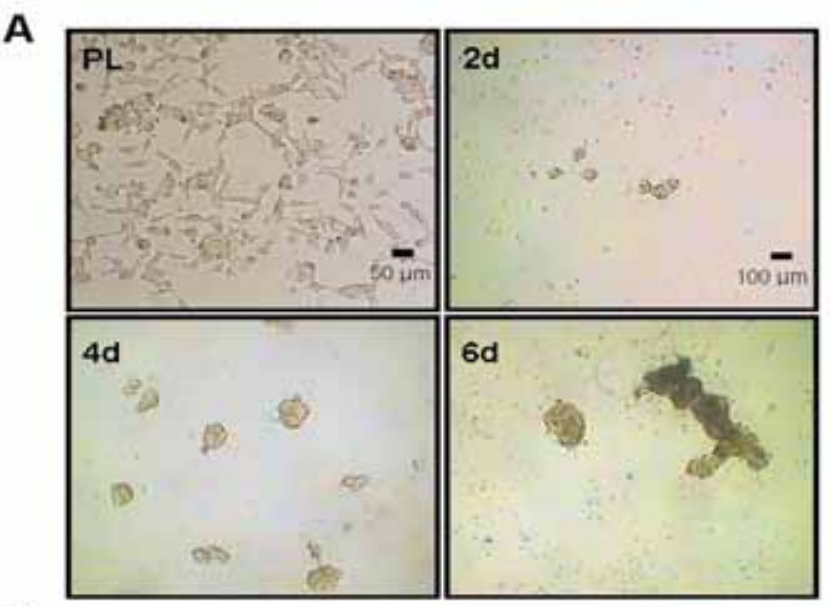

B

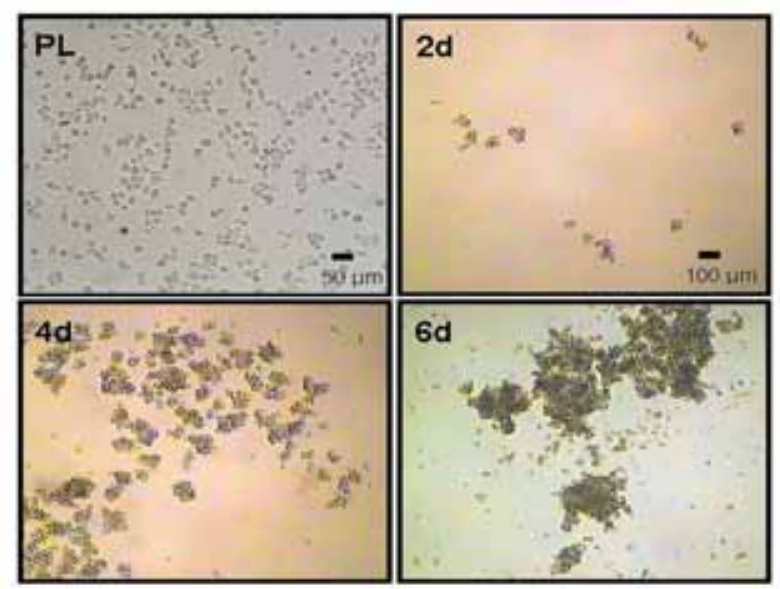

C

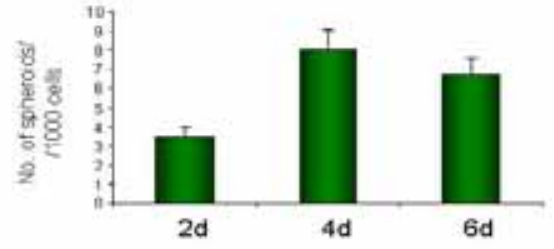

D

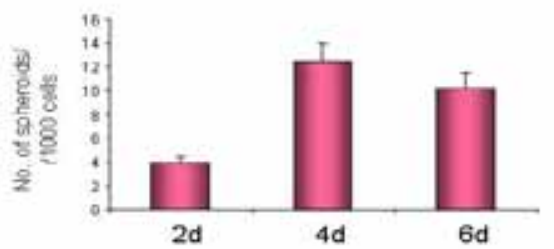

Figure 1: Morphological changes of (A) LNCaP and (B) PC3 prostate cancer cells grown in different culture conditions. $\mathbf{C}$ and $\mathbf{D}$, numbers of cell spheroids in $\mathbf{A}$ and $\mathbf{B}$, respectively. PL, plastic (2D cell cultures); 2-4-6d, 2-4-6 days of 3D cell culture. Data in $\mathbf{C}$ and $\mathbf{D}$ are expressed as means $\pm S D$ from three independent experiments. 
Citation: Miceli V, Cocciadiferro L, Maurizio Z, Kang KS, Trosko JE, et al. (2011) Molecular Profiling of Potential Human Prostate Cancer Stem Cells. J Stem Cell Res Ther S7:001. doi:10.4172/2157-7633.S7-001

Ltd. Cambridge, England). Quantification of immunostaining was performed on digitized images representing at least 10 randomly selected fields for each sample. The proportion (\%) of positive stain was calculated as the ratio of the total area of positively stained cells over the total area of cell nuclei using a color discrimination software.

A
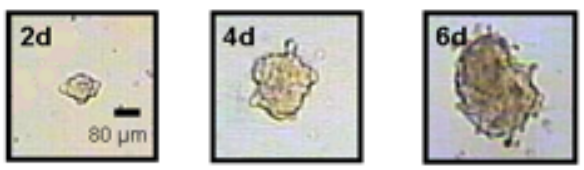

B

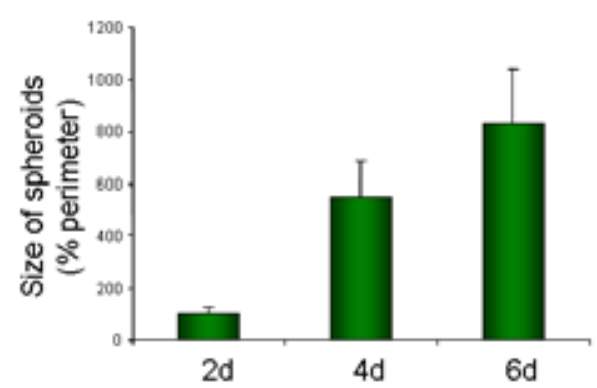

\section{Statistics}

The data were expressed as the mean \pm the standard deviation. Analyses were performed using computerized statistical software. The data were analyzed by Dunnet's t-tests. Differences were considered statistically significant at $\mathrm{P}<0,05$.

C
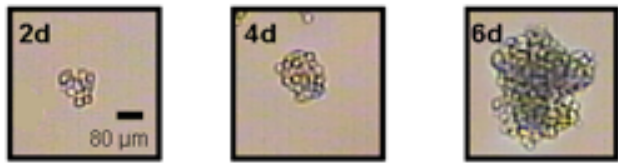

D

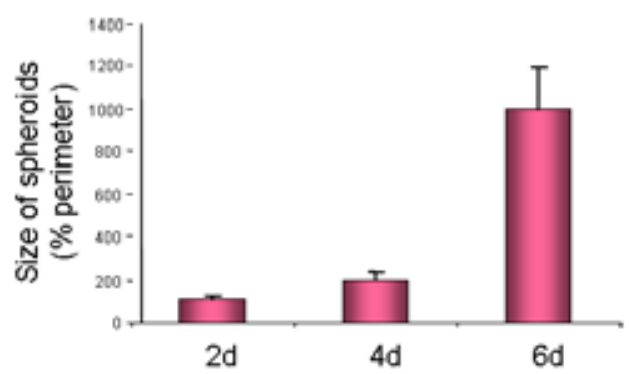

Figure 2: Morphology and size of $\mathrm{LNCaP}(\mathrm{A}, \mathrm{B})$ and PC3 (C, D) cell spheroids. Data represent means $\pm S D$ from three independent experiments. 2-4-6d, 2-4-6 days of $3 \mathrm{D}$ cell cultures.

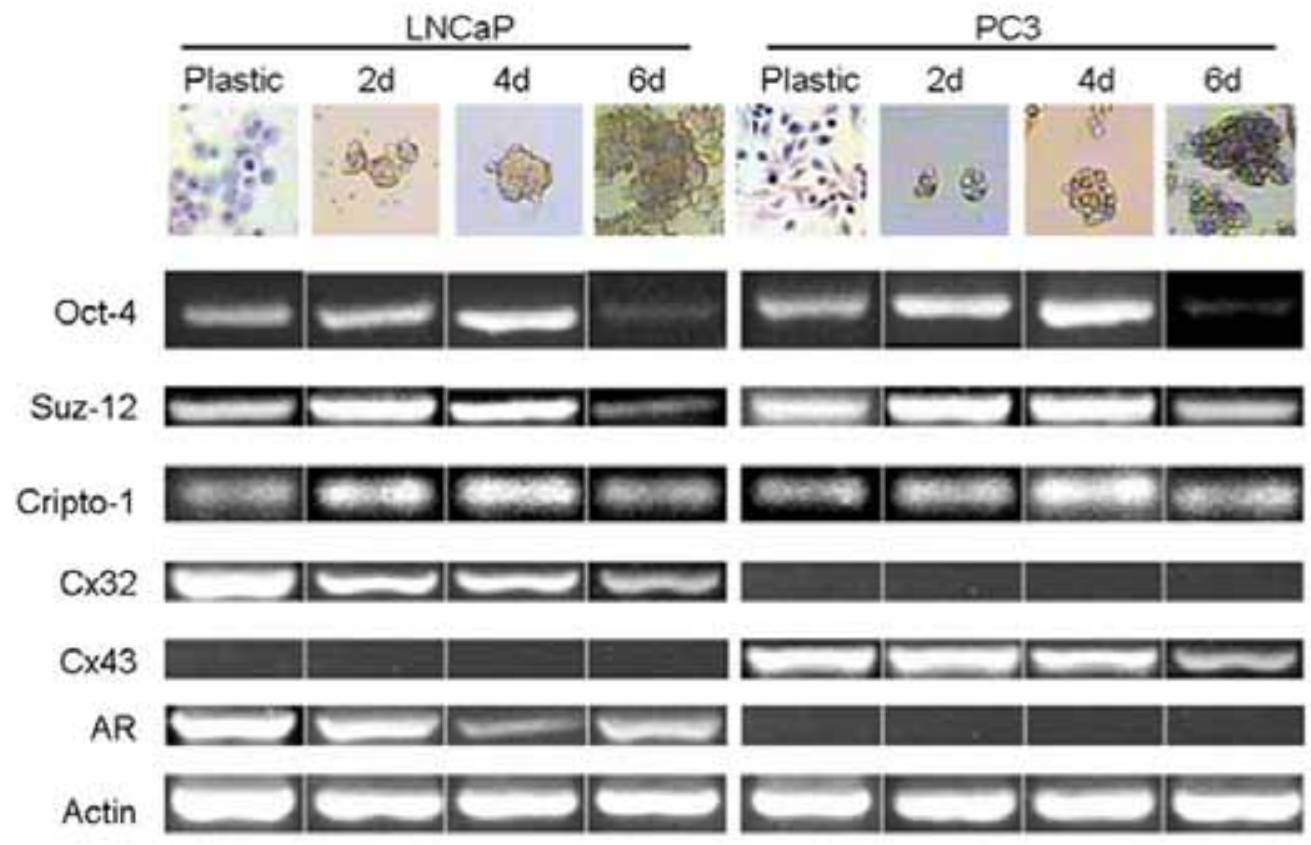

Figure 3: Expression of selected cell markers in LNCaP and PC3 human prostate cancer cells. The figure illustrates the expression of PCR products corresponding to mRNAs encoding three putative stem cell markers (Oct-4, Suz-12 and Cripto-1) and three cell differentiation markers (Cx32, Cx43 and AR) in different cell cultures conditions. The data shown are representative of at least 3 independent experiments. $\beta$-actin was used as a housekeeping gene. Plastic (2D cell cultures); $2-4-6 \mathrm{~d}$, 2-4-6 days of 3D cell cultures. 


\section{Results}

\section{Growth of human prostate cancer cell lines in anchorage- independent (3D) cell culture conditions}

Both androgen responsive LNCaP cells and nonresponsive PC 3 cells generated multiple cell aggregates when grown in KSF medium under conditions that do not allow cells to adhere to the plastic substrate (see Figure 1). Two days after plating, many cells died, but limited number survived and generated floating spherical cell colonies. The LNCaP cells efficiently gave rise to compact, rounded cell spheroids (Figure 1A) that, as previously reported for the "mammospheres", are likely to include extracellular matrix (ECM) components [46]. Conversely, PC3 cell failed to form regular structures, but produced multiple cell aggregates, variable in both number and size (Figure 1B). Overall, the number of cell spheroids increased after 4 days, although it was much lower in LNCaP cells than in PC3 cells (Figure 1C and 1D). In addition, the size of cell spheroids increased continuously up to day six, when relatively large cell colonies (up to $150 \mu \mathrm{m}$ diameter) could be observed in either cell line (Figure 2).

After six days, cell spheroids readily formed clusters, resulting in a reduction of the spheroids number (Figure $1 \mathrm{C}$ and 1D). Furthermore, a proportion (20-30\%) of floating cell spheroids and/or cell aggregates attached to the plastic and displayed a differentiated phenotype consisting of cells spreading out of the attached clusters as a ringshaped monolayer of epithelial tumor cells (not shown). Cell viability was consistently in the range of $93-97 \%$ throughout the $3 \mathrm{D}$ culturing.

\section{RT-PCR analysis}

Aiming to assess the expression of presumptive markers of prostate cancer stem cells and cancer non-stem cells, we investigated a few candidate genes in different cell culture conditions using semiquantitative RT-PCR method. In particular, the expression of Oct4, Suz-12, Cripto-1 (stem/progenitor cell markers), as well as of Cx32, Cx43 and AR (cell differentiation markers) was measured. Putative stem cell markers are elevated in PC3 cells with respect to LNCaP cells in 2D cell cultures (not shown); on the other hand, $\mathrm{Cx} 43$ is expressed only in PC3 cells, while Cx32 and AR are expressed solely in LNCaP cells (see Figure 3). When both cells lines were grown in conditions that do not allow adhesion to the plastic substrate (3D cell cultures), the expression levels of candidate cancer stem cells markers initially increased (days 2-4) but drastically fell thereafter (days 6) (see Figure 4). On the other hand, the expression of the presumptive markers of cancer non stem - partly differentiated - cells, namely Cx32 and AR in LNCaP cells, Cx43 in PC 3 cells, decreased gradually from day 2 to 6 as opposed to cancer stem cell markers (see Figure 3).

\section{Immunohistochemical assay (ICA)}

The expression of candidate cancer stem cell and non-stem cell markers, was also determined at protein level using ICA both on cells grown directly on slides (2D cell cultures) and on spheroid-derived cell cytospins (3D cell cultures). Overall, data of ICA for any cell marker were largely in accordance to what observed using RT-PCR analysis. In particular, Oct-4, Suz-12 and Cripto-1 were expressed to a greater extent in PC3 cells with respect to LNCaP cells in both $2 \mathrm{D}$ and $3 \mathrm{D}$ cell culture conditions. However, the expression levels of stem cell markers raised markedly in both cell lines when grown in $3 \mathrm{D}$ as compared to $2 \mathrm{D}$ culture conditions, with a range of 2.4-6.9 fold increase in LNCaP cells
A

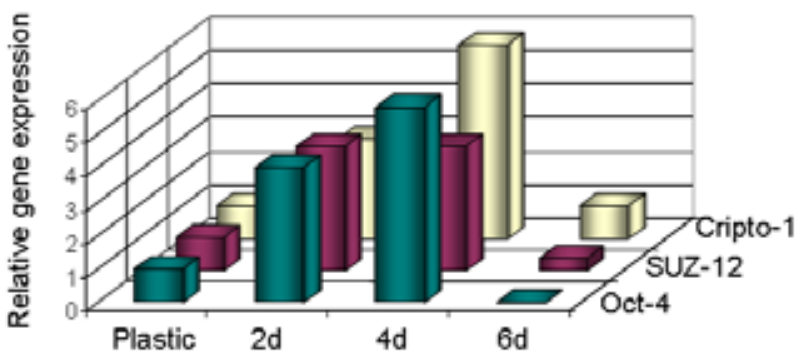

B

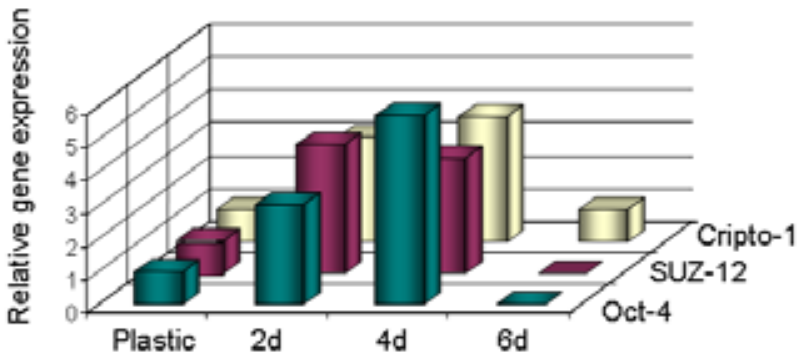

Figure 4: Expression of Oct-4, Suz-12 and Cripto-1 genes in PC3 (A) and LNCaP (B) prostate tumor cell. RNA was isolated and subjected to RT-PCR analysis; the amplified gene products were quantified by densitometric analysis and normalized to $\beta$-actin. (Student's t-test, $p<0.05$ ). Plastic (2D cell cultures); 2-4-6d, 2-4-6 days of 3D cell cultures.

A

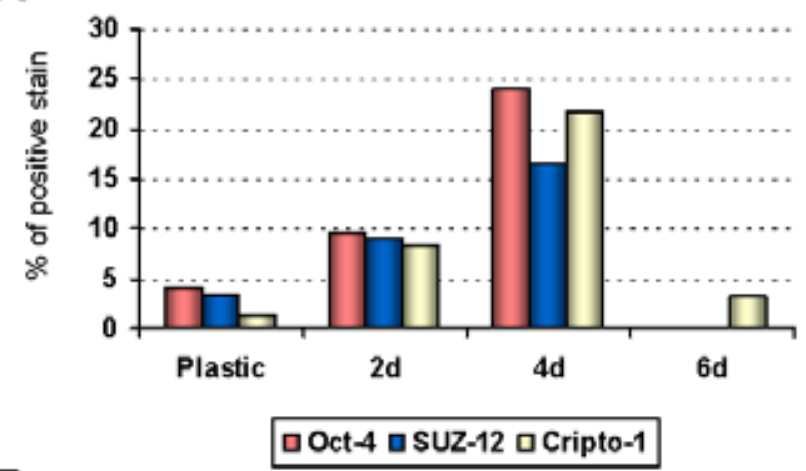

B

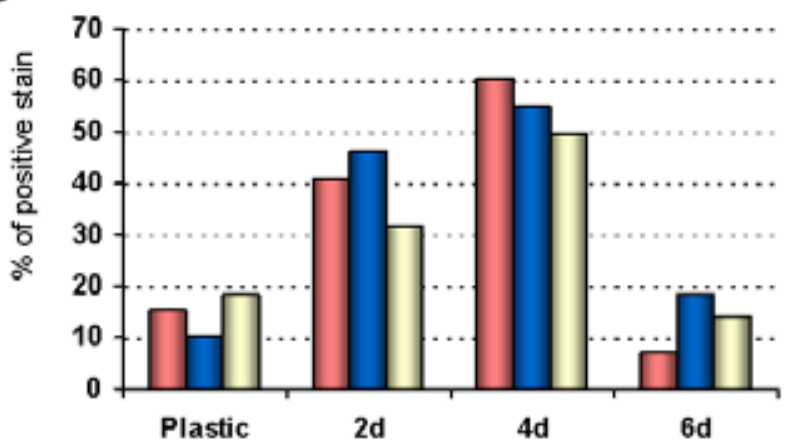

Figure 5: Expression of Oct-4, Suz-12 and Cripto-1 protein in LNCaP (A) and PC3 (B) prostate tumor cells. Both cells grown directly on plastic slides (2D) and cytospins originated from cell spheroids (3D) were stained for the selected markers using ICA as described in materials and methods. Values represent average $\%$ of positively stained cells from 2 independent experiments performed in triplicate. 
Citation: Miceli V, Cocciadiferro L, Maurizio Z, Kang KS, Trosko JE, et al. (2011) Molecular Profiling of Potential Human Prostate Cancer Stem Cells. J Stem Cell Res Ther S7:001. doi:10.4172/2157-7633.S7-001

PL

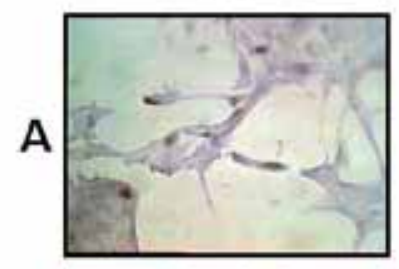

B

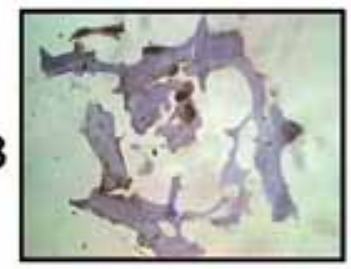

c
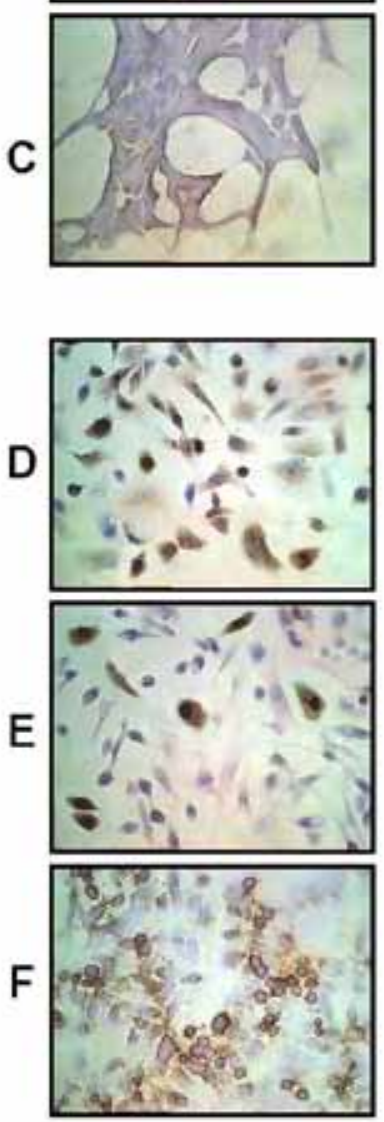

2d
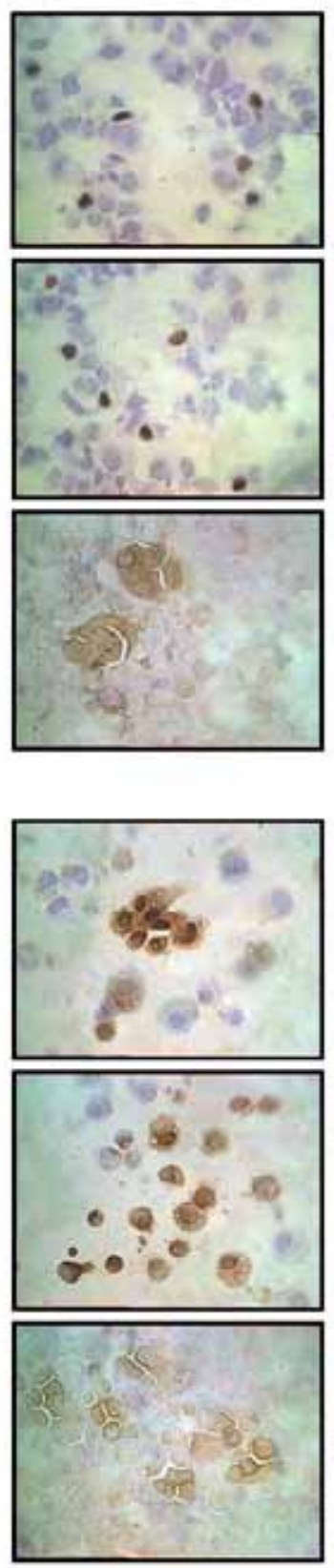

$4 d$
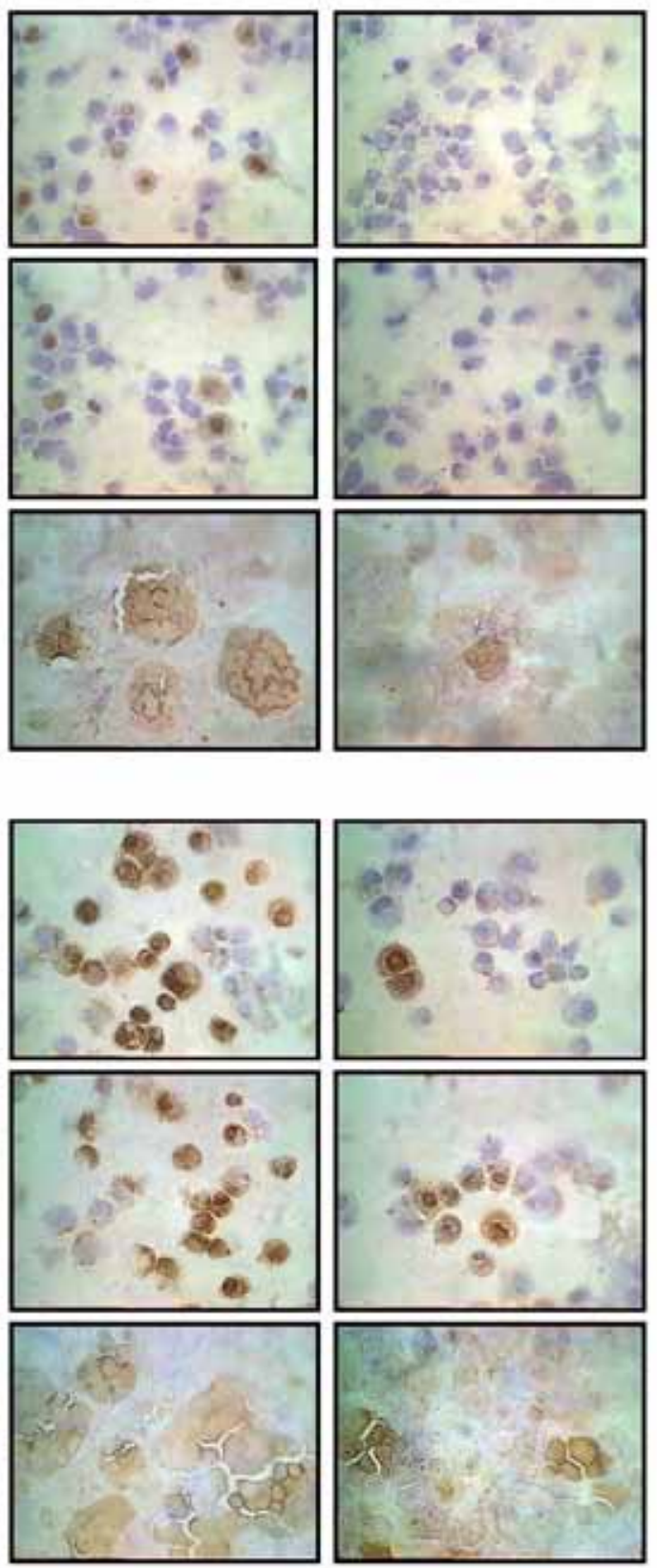

$6 d$
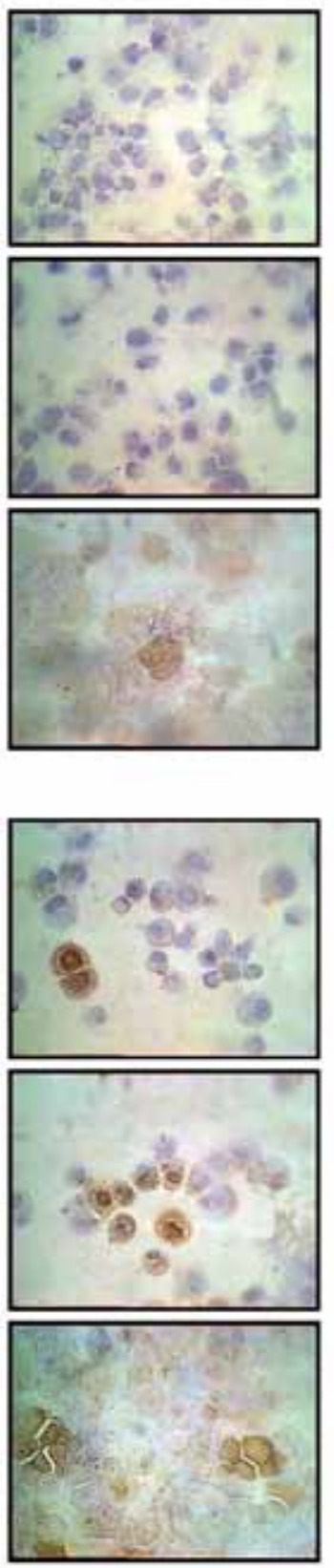

Figure 6: Immunocytochemical assay of Oct-4, Suz-12 and Cripto-1 in LNCaP and PC3 cells. A, B, and C: staining for Oct-4, Suz-12, and Cripto-1, respectively, in LNCaP cells; $\mathbf{D}$, E, and F: staining for Oct-4, Suz-12, and Cripto-1, respectively, in PC3 cells

For the assay either cells grown directly on plastic slides (2D) or cytospins originated from cell spheroids (3D) were used. For methodological details see text.

and 1.7-4.3 fold increase in PC3 cells. Furthermore, 3D cell cultures of both LNCaP and PC3 cells showed a steady increase in all the three markers by days 2 and 4 , with a consistent, significant decrease of their expression being observed at day 6 (Figure 5).

Figure 6 illustrates ICA of cancer stem cell and cell differentiation markers in LNCaP and PC3 cells. Interestingly, staining for both Oct4 and Suz-12 was localized predominantly in the nucleus but also in cytoplasm of PC3 cells and, to a much lesser extent, of LNCaP cells. As expected, Cripto-1 staining was exquisitely located on the cell membrane of both cell lines. Cellular localization of staining for the three different presumptive cancer stem cell markers did not change comparing $2 \mathrm{D}$ and $3 \mathrm{D}$ culture conditions. It is noteworthy that PC3 cells, also, showed positive cytoplasmic staining for Oct- 4 in the absence or presence of nuclear staining and this was especially true in cells undergoing mitosis. Therefore, dividing cells gave rise to figures where both nuclei were Oct- 4 positive $\left(\mathrm{Oct} 4^{+} / \mathrm{Oct}-4^{+}\right)$or one daughter cell had an Oct $4^{+}$nucleus and the other had an Oct4 nucleus (data not shown). 
As far as cell differentiation markers are concerned, no expression of connexins and/or androgen receptor could be detected using ICA in $3 \mathrm{D}$ culture conditions at any time. Cells cultured in 2D conditions (plastic) showed expression of AR and Cx32 in LNCaP cells, while PC3 cells expressed solely Cx43, in accordance to what observed using RTPCR analysis (not shown).

\section{Discussion}

In this study we have investigated the expression of both presumptive cancer stem cell markers and cell differentiation markers in two established human prostate cancer cells, LNCaP and PC3, aiming to define molecular profiles of potential cancer stem and cancer non-stem cells within either cell line. In particular, Oct-4, Suz-12 and Cripto- 1 were selected as cancer stem cell markers, while AR, Cx43, and $\mathrm{C} \times 32$ were used as cancer non stem cell markers.

When multiple human cancer cells, which have been in culture under different conditions for years, are assessed for their clonal growth and clonogenic ability, only a small percentage of cells possess such potentials [47]. Neural stem cells, cultured in suspension, form clusters of cells, called "neurospheres" that display an increased capacity for selfrenewal [48]. Furthermore, two important studies [46,49], respectively, used mammosphere-derived cells and neurosphere-derived cells to determine genes up-regulated in stem cells. In the present study, we have used anchorage-constrained cell culture conditions in serum-free, low calcium culture media to prevent or delay differentiation and to foster the clonal expansion of putative cancer stem cells. Under this condition, we have determined the expression of stemness genes at both transcript and protein level, also in comparison with cells cultured in routine $2 \mathrm{D}$ conditions. The presumptive cancer stem cell markers we have inspected were: (a) Oct-4, a member of the POU family that acts as a transcription factor [27]; (b) Suz-12, a member of the polycomb group family that functions as an epigenetic chromatin modifier [37]; and (c) Cripto-1, a member of the EGF-CFC growth factor family that functions as co-receptor for the transforming growth factor-beta family of protein or as ligand through a Nodal/Alk4-indipendent signaling pathway [40]. Three markers of differentiated cells were also assessed: $\mathrm{Cx} 32, \mathrm{Cx} 43$ and AR.

Human LNCaP and PC3 prostate cancer cells grown in 3D culture conditions readily generated spheroid-like structures or more irregular cell aggregates of viable cells, respectively. It is supposed that, under this condition, the late progenitor and/or transit-amplifying cells died, while potential stem cells and/or early progenitor cells survived and clonally proliferated.

It has previously been reported that "neurospheres" generated by neural stem cells comprise between $4 \%$ and $20 \%$ of the mature neurospheres, the remaining cells representing progenitor cells in various stages of differentiation [45]. Our results are consistent with this model in that the expression of cancer stem cell genes is in the same range (LNCaP, 1.2-4.1\%; PC3, 10.6-18.2\%) in cells grown in 2D conditions, while it remarkably increases in $3 \mathrm{D}$ cell cultures up to day 4. After day 4, the presence of a significant number of cell aggregates triggers the formation of rather large cell clusters, resulting in an increase in their size and in a reduction of their number.

The assumption that the composition of cell spheroids/aggregates changes towards a clonal expansion of cancer stem cells is supported by the evidence that the expression of stemness genes, including Oct-4, Suz-12, and Cripto-1, increases up to day 4 of 3D conditions, while that of cell differentiation markers consistently decreased. The significant decline of presumptive prostate cancer stem cell markers observed at day 6 of $3 \mathrm{D}$ cultures is presumably a consequence of the initial occurrence of cell attachment and differentiation, and is also reflected in the rise of $\mathrm{AR}$ transcript, while $\mathrm{Cx} 32$ and $\mathrm{Cx} 43$ continued to decrease. This seeming discrepancy is presumably based on the fact that connexin genes are late differentiation genes, requiring the preliminary establishment of cell-cell and cell-matrix interaction, while AR is a gene that becomes activated at very early stages during androgen-directed maturation and glandular differentiation of prostate epithelial cells.

The evidence that all three stemness genes are elevated in PC3 cells with respect to LNCaP cells is consistent with the view that the number of cancer stem cells within a given tumor may well be heterogeneous, but should increase invariably with the progression of disease and become higher in distant metastasis as compared with either primary tumor or locally involved nodes. Since PC3 cells were originated from a bone metastatic lesion while LNCaP cells have been originally established from a lymphnode metastasis of a human prostate adenocarcinoma, one would expect to find a larger fraction of PC 3 cell population being composed by putative cancer stem cells. This concept, however, needs to be corroborated by direct experimental evidence comparing the frequency of cancer stem cells in both the primary and metastatic tumors, as many other factors (including genetic and epigenetic instability that might occur during the transition from the primary towards the metastatic state, as well as the clonal selection of cultured cells) may differentially affect the control of symmetrical versus asymmetrical cell division of the cancer stem cells in a given tumor and the expression of cancer stem cell markers in "in vitro" cell model systems.

In PC3 cells, the presence of symmetrical $\left(\mathrm{Oct} 4^{+} / \mathrm{Oct}^{+}\right.$nuclei of daughter cells) and asymmetrical (Oct4 $4^{+} / \mathrm{Otc}^{-}$nuclei) cell divisions, in both $2 \mathrm{D}$ and $3 \mathrm{D}$ cell culture conditions, can be interpreted to indicate that the Oct- 4 expressing cells are the potential "cancer stem cells", whereas the Oct- 4 negative cells are the putative cancer non-stem cells, in accordance to the definition of a cancer stem cell as being uniquely capable of dividing both symmetrically and asymmetrically. The presence of cytoplasmic staining for the two stemness genes, Oct- 4 and Suz-12, in both cell lines implies that biologically relevant mechanisms, as yet unknown, might regulate the cellular compartimentalization of these important protein products. In the case of Oct-4, there is some indication that two isoforms (A and B) exist and that they have different patterns of expression and localization within a stem cell [50].

A major goal of this work was to profile the expression of three candidate gene markers aiming to define a molecular portrait of potential prostate cancer stem cells. This issue is of critical importance for a better understanding of prostate cancer development and for either prognostic or therapeutic purposes, since prostate stem cells are believed to be the target cells of prostate carcinogenesis and prostate cancer stem cells are supposed to be the drivers of tumor progression and resistance to treatment.

In our hands, Oct- $4^{+} / \mathrm{Suz}-12^{+} /$Cripto- $1^{+}$cells are likely to represent potential human prostate cancer stem or early progenitor cells. In particular, Oct- 4 is a highly promising candidate marker since the 
expression levels of this gene are strictly associated to the presence and number of cancer stem cells, being significantly upregulated under conditions that favor their clonal expansion and drastically downregulated when prostate tumor cells develop differentiated phenotypes. In this respect, this cell model system might prove useful to test several tumor promoters and/or chemotherapeutic agents, to provide prognostic indication and to predict the ability of patients to respond to current therapeutic agents. However, further studies are needed to inspect the ability of the potential human prostate cancer stem or progenitor cells $\left(\mathrm{Oct}-4^{+} / \mathrm{Suz}-12^{+} / \mathrm{Cripto}^{-1}\right)$ we have isolated from cultured prostate cancer cells to induce tumor formation in recipient animal models.

\section{Acknowledgements}

These studies were partially supported by a grant of the Italian Ministry of Health (Molecular mechanisms controlling cancer stem cells survival, RFSIC-2006-335442) to GC.

\section{References}

1. Trosko JE, Tai MH (2006) Adult stem cell theory of the multi-stage, multimechanism theory of carcinogenesis: Role of inflammation on the promotion of initiated cells. In Infection and Inflammation: Impacts on Oncogenesis. Contrib Microbiol 13: 45-65.

2. Sell S (1993) Cellular origin of cancer: dedifferentiation or stem cell maturation arrest? Environ Health Perspect 101: 15-26.

3. Trosko JE, Chang CC, Wilson MR, Upham B, Hayashi T, et al. (2000) Gap junctions and the regulation of cellular functions during development and differentiation. Methods 20: 245-264.

4. Markert CL (1968) Neoplasia: a disease of cell differentiation. Cancer Res 28 1908-1914.

5. Pierce GB (1974) Neoplasms, differentiation, and mutations. Am J Pathol 77 103-118.

6. Potter VR (1978) Phenotypic diversity in experimental hepatomas: the concept of partially blocked ontogeny. Br J Cancer 38: 1-23.

7. Fialkow PJ (1979) Clonal origin of human tumors. Annu Rev Med 30: 135-143.

8. Nowell PC (1976) The clonal evolution of tumor cell population. Science 194: 23-28.

9. Shamblott MJ, Axelman J, Wang S, Bugg EM, Littlefield JW, et al. (1998) Derivation of a pluripotent stem cell from cultured primordial germ cells. Proc Natl Acad Sci USA 95: 13726-13731.

10. Thomson JA, Itskovitz-Eldor J, Shapiro SS, Waknitz MA, Swiergiel JJ, et al. (1998) Embryonic stem cell lines derived from human blastocyts. Science 282 $1145-1147$.

11. Al-Hajj M, Wicha MS, Benito-Hernandez A, Morrison SJ, Clarke MF (2003) Prospective identification of a tumorigenic breast cancer cells". Proc Natl Acad Sci USA 100: 3983-3988.

12. Ponti D, Costa A, Zaffaroni N, Pratesi G, Petrangolini G, et al. (2005) Isolation and In vitro propagation of tumorigenic breast cancer cells with stem/progenitor cell properties. Cancer Res 65: 5506-5511.

13. Wang J, Guo LP, Chen LZ, Zeng YX, Lu SH (2007) Identification of cancer stem cell-like side population cells in human nasopharyngeal carcinoma cell line. Cancer Res 67: 3716-3724.

14. Hermann PC, Huber SL, Herrler T, Aicher A, Ellwart JW, et al. (2007) Distinct populations of cancer stem cells determine tumor growth and metastatic activity in human pancreatic cancer. Cell Stem Cell 1: 313-323.

15. Miki J, Furusato B, Li H, Gu Y, Takahashi H, et al. (2007) Identification of putative stem cell markers, CD133 and CXCR4, in hTERT-immortalized primary non-malignant and malignant tumor-derived human prostate epithelial cell lines in prostate cancer specimens. Cancer Res 67: 3153-3161.
16. Ho MM, Ng AV, Lam S, Hung JY (2007) Side population in human lung cancer cell lines and tumors is enriched with stem-like cancer cells. Cancer 67: 48274833.

17. Chang CC, Trosko JE, el-Fouly MH, Gibson-D'Ambrosio RE, D'Ambrosio SM (1987) Contact insensitivity of a subpopulation of normal human fetal kidney epithelial cells and of human carcinoma cell lines. Cancer Res 47: 1634-1645.

18. Lazzeri E, Crescioli C, Ronconi E, Mazzinghi B, Sagrinati C, et al. (2007) Regenerative potential of embryonic renal multipotent progenitors in acute renal failure. J Am Soc Nephrol 18: 3128-3138.

19. Kao CY, Nomata K, Oakley CS, Welsch CW, Chang CC (1995) Two types of normal human breast epithelial cells derived from reduction mammoplasty: phenotypic characterization and response to SV40 transfection. Carcinogenesis 16: $531-538$

20. Linning KD, Tai MH, Madhukar BV, Chang CC, Reed DN Jr et al. (2004) Redox-mediated enrichment of self-renewing adult human pancreatic cells that possess endocrine differentiation potential. Pancreas 29: 64-76.

21. Lin TM, Chang HW, Wang KH, Kao AP, Chang CC, et al. (2007) Isolation and identification of mesenchymal stem cells from human lipoma tissue. Biochem Biophys Res Comm 361: 883-889.

22. Herrera MB, Bruno S, Buttiglieri S, Tetta C, Gatti S, et al. (2006) Isolation and characterization of a stem cell population from adult human liver. Stem Cells 24: $2840-50$

23. Huss WJ, Gray DR, Werdin ES, Funkhouser WK Jr, Smith GJ (2004) Evidence of pluripotent human prostate stem cells in a human primary xenograft model. Prostate 60: 77-90.

24. Schmelz M, Moll R, Hesse U, Prasad AR, Gandolfi JA, et al. (2005) Identification of a stem cell candidate in a normal human prostate gland. Euro J Cell Biol 84 341-354.

25. Rizzo S, Attard G, Hudson DL (2005) Prostate epithelial stem cells. Cell Prolif 38: $363-374$

26. Okamoto K, Okazawa H, Okuda A, Sakai M, Muramatsu M, et al. (1990) A novel octamer binding transcription factor is differentially expressed in mouse embryonic cells. Cell 60: 461-472.

27. Rosner MH, Vigano MA, Ozato K, Timmons PM, Poirier F, et al. (1990) A POUdomain transcription factor in early stem cells and germ cells of the mammalian embryo. Nature 345: 686-692.

28. Deyev IE, Polanovsky OL (2004) The Oct genes and Oct proteins. Mol Bio 38: $40-46$

29. Monk M, Holding C (2001) Human embryonic genes re-expressed in cancer cells. Oncogene 20: 8085-8091.

30. Tai MH, Chang CC, Kiupel M, Webster JD, Olson LK, et al. (2005) Oct-4 expression in adult human stem cells: evidence in support of the stem cell theory of carcinogenesis. Carcinogenesis 26: 495-502.

31. Webster JD, Yuzbasiyan-Gurkan V, Trosko JE, Chang CC, Kiupel M (2007) Expression of the embryonic transcription factor Oct4 in canine neoplasms: A potential marker for stem cell subpopulations in neoplasia. Vet Pathol 44 893-900.

32. Atlasi Y, Mowla SJ, Ziaee SA, Bahrami AR (2007) Oct-4, an embryonic stem cell maker is highly expressed in bladder cancer. Int J Cancer 120: 1598-1602.

33. Chiou SH, Yu CC, Huang CY, Lin SC, Liu CJ, et al. (2008) Positive correlations of Oct-4 and nanog in oral cancer stem-like cells and high-grade oral squamous cell carcinoma. Clin Cancer Res 14: 4085-4095.

34. Liedtke S, Enczmann J, Waclawczyk S, Wernet P, Kögler G (2007) Oct4 and its pseudogenes confuse stem cell research. Cell Stem Cell 1: 364-366.

35. Holden C (2006) Gene-suppressing proteins reveal secrets of stem cells Science 21: 312: 349 .

36. Boyer LA, Lee TI, Cole MF, Johnstone SE, Levine SS, et al. (2005) Core transcriptional regulatory circuitry in human embryonic stem cells. Cell 122 947-956. 
Citation: Miceli V, Cocciadiferro L, Maurizio Z, Kang KS, Trosko JE, et al. (2011) Molecular Profiling of Potential Human Prostate Cancer Stem Cells. J Stem Cell Res Ther S7:001. doi:10.4172/2157-7633.S7-001

37. Kirmizis A, Bartley SM, Farnham PJ (2003) Identification of the polycomb group protein $\mathrm{SU}(\mathrm{Z}) 12$ as a potential molecular target for human cancer therapy. Mol Cancer Ther 2: 113-121.

38. Squazzo SL (2006) Suz12 binds to silenced regions of the genome in a celltype-specific manner. Genome Res 16: 890-900.

39. Jones PA, Baylin SB (2002) The fundamental role of epigenetic events in cancer. Nat Rev Genet 3: 415-428.

40. Bianco C, Strizzi L, Normanno N, Khan N, Salomon DS (2005) Cripto-1: an oncofetal gene with many faces. Curr Top Dev Biol 67: 85-133.

41. Minchiotti G, Parisi S, Liguori G, Signore M, Lania G, et al. (2000) Membrane anchorage of Cripto protein by glycosylphosphatidylinositol and its distribution during early mouse development. Mech Dev 90:133-142.

42. Bianco C, Normanno N, Salomon DS, Ciardiello F (2004) Role of the cripto (EGF-CFC) family in embryogenesis and cancer. Growth Factors 22: 133-139.

43. Trosko JE, Ruch RJ (1998) Cell-cell communication in carcinogenesis. Front Biosci 3: 208-236.

44. Hayflick $L$ (1965) The limited in vitro lifetime of human diploid cell strains Exp. Exp Cell Res 37: 614-636.
45. Scheffler B, Horn M, Blumcke I, Laywell ED, Coomes D, et al. (1999) Marrowmindedness: A perspective on neuropoiesis. Trends Neurosci 22: 348-357.

46. Dontu G, Abdallah WM, Foley JM, Jackson KW, Clarke MF, et al. (2003) In vitro propagation and transcriptional profiling of human mammary stem/progenitor cells. Genes Dev 17: 1253-1270.

47. Patrawala L, Calhoun T, Schneider-Broussard R, Zhou J, Claypool K, et al (2005) Side Population Is Enriched in Tumorigenic, Stem-Like Cancer Cells, whereas ABCG2+ and ABCG2- Cancer Cells Are Similarly Tumorigenic. Cancer Res 65: 6207-6219.

48. Ivanova NB, Dimos JT, Schaniel C, Hackney JA, Moore KA, et al. (2002) A stem cell molecular signature. Science 298: 601-604.

49. Ramalho-Santos M, Yoon S, Matsuzaki Y, Mulligan RC, Melton DA (2002) "Stemness": transcriptional profiling of embryonic and adult stem cells. Science 298: 597-600.

50. Cauffman G, Van de Velde H, Liebaers I, Van Steirteghem A (2005) Oct-4 mRNA and protein expression during human preimplantation development. Mol Hum Reprod 11: 173-181. 